\title{
Third ventriculostomy vs ventriculoperitoneal shunt in pediatric obstructive hydrocephalus: results from a Swiss series and literature review
}

\author{
Sandrine de Ribaupierre $\cdot$ B. Rilliet $\cdot \mathbf{O}$. Vernet • \\ L. Regli • J.-G. Villemure
}

Received: 6 September 2006 /Published online: 17 January 2007

(C) Springer-Verlag 2007

\begin{abstract}
Introduction Few series compare endoscopic third ventriculostomies (ETV) and ventriculoperitoneal shunts (VPS). To avoid the complications after a shunt insertion, there is an increased tendency to perform a third ventriculostomy. We reviewed all pediatric patients operated in the French-speaking part of Switzerland for a newly diagnosed obstructive hydrocephalus since 1992 and compared the outcome of patients who benefited from ETV to the outcome of patients who benefited from VPS. There were 24 ETV and 31 VPS.

Discussion At 5 years of follow-up, the failure rate of ETV was $26 \%$, as compared to $42 \%$ for the VPS group. This trend is also found in the pediatric series published since 1990 (27 peer-reviewed articles analyzed).

Conclusion In accordance to this trend, although a statistical difference cannot be assessed, we believe that ETV should be the procedure of choice in pediatric obstructive hydrocephalus.
\end{abstract}

\footnotetext{
S. de Ribaupierre $\cdot$ B. Rilliet $\cdot \mathrm{O}$. Vernet $\cdot$ L. Regli $\cdot$

J.-G. Villemure

Department of Neurosurgery, CHUV,

Lausanne, Switzerland

B. Rilliet

Department of Neurosurgery, HUG,

Geneva, Switzerland

S. de Ribaupierre $(\bowtie)$

Service de Neurochirurgie, CHUV,

Rue du Bugnon,

1011 Lausanne, Switzerland

e-mail: s_derib@hotmail.com
}

Keywords Pediatric · Hydrocephalus · Ventriculostomy · Ventriculoperitoneal shunt

\section{Introduction}

In the last decades, endoscopic third ventriculostomy (ETV) has become the procedure of choice in the treatment of pediatric obstructive hydrocephalus in many centers, replacing ventriculoperitoneal shunts (VPS). Even if the procedures might seem simple, the pathophysiology of hydrocephalus is complex and probably not completely understood; therefore, management of patients with hydrocephalus can be challenging. Since the introduction of the shunt, many new materials have been developed, with each development bringing the hope that the new materials will lead to a better outcome. Some surgeons think that endoscopic third ventriculoscopy was the key to success in the cure of hydrocephalus, but does its outcome confirm that thought? Many articles have been published concerning the mortality and morbidity, as well as the outcome, of both approaches. Ventriculo-atrial and VPS have been compared, as well as different types of valves for VPS, but the comparison between third ventriculostomies and cerebrospinal fluid shunts has rarely been addressed.

We studied all pediatric patients diagnosed with obstructive hydrocephalus who were treated in Geneva or Lausanne, Switzerland since 1990. After analyzing the two groups, their outcome and failure rate, we retrieved the last pediatric series published in peer-reviewed literature (on ventriculostomy or VPS from 1990 to June 2006) to compare the two procedures and to see if a difference could be seen in their outcomes. A strict meta-analysis of those series is not possible, as there are, for the moment, no randomized controlled trials. 


\section{Materials and methods}

All pediatric patients ( $0-18$ years old) who were diagnosed and treated for the first time for obstructive hydrocephalus, in Lausanne or Geneva, Switzerland, from January 1990 to December 2004 were retrospectively analyzed. There were 24 ETV and 31 VPS performed. Data were analyzed with respect to etiology of hydrocephalus, age, and gender. We compared the operative indications, and in the case of failure, the mean time before revision, the causes of failures, and their risk factors. Failure was defined as the need of a surgical intervention, and included shunt revision, placement of a new shunt, or a new ventriculostomy.

The literature was reviewed using PubMed and Embase, from 1990 to June 2006 with the key words "obstructive hydrocephalus" and "pediatric", in peer-reviewed journals. Tables of content of the major pediatric neurosurgical journals (Child's Nervous System, Journal of Neurosurgery: Pediatrics, and Pediatric Neurosurgery) were reviewed as well from 2000 to 2006. All pediatric series that involved more than ten patients and analyzed either third ventriculostomy, shunt procedures, or both were included. Articles describing a technique or only focusing on a special type of complication were not included, unless the general success rate (or failure) and follow-up time were stated. When different articles were written with the same or only slightly different population (for example two studies in the same center overlapping), only one of the articles was included to avoid including the same patients twice. If a series mixed pediatric and adult patients, it was discarded, unless the pediatric population was easily identified. If a series included both obstructive and communicating hydrocephalus, we would consider it only if there was a majority of obstructive patients or if we could separately analyze obstructive patients. In series that included first-time shunts and revisions, we only accounted for the first-time surgery when that was possible. A total of 27 studies were retrieved and included.

Data were analyzed using Student's $t$-test, KaplanMeier, and analysis of variance (Statistica 6.0, StatSoft).

\section{Results}

There was a total of 48 patients included. Seven of them had both procedures; therefore, there were 55 new procedures. The mean age of the total population was 4.6 years old (median 8.8 months, 1 day to 17 years). Twenty-four $(50 \%)$ patients had a failure of their first operation and needed revision. The mean number of revisions was $1.28(0-15$ times). The mean revision-free time was 22 months (median 4.6 months, 1 day-9 years). The follow-up period was 4.4 years (median 39 months).
Third ventriculostomies (ETV)

A total of 24 new ventriculostomies were performed. The patients had a mean age of 6.1 years (median 6 years, 23 days to 17 years old). There were 7 girls and 17 boys. Patients who had had their shunt inserted during the inclusion period and had an ETV after the first shunt failure were also considered in this category (two patients).

There were 11 patients with an aqueductal stenosis, 6 patients with a posterior fossa lesion (four posterior fossa tumors and two cysts), 5 patients with a tectal or tegmental lesion, and 2 patients with another obstructive etiology (membranes in aqueduct after toxoplasmosis, Chiari I).

Eight patients had a failure of their ventriculostomy $(33 \%)$, leading to a new procedure. In three cases, they underwent a re-ventriculostomy, whereas five patients had a VPS implanted. The mean revision-free time was 19 months (median 1 month, 13 days -9 years). The mean number of revisions was 0.33 times $(0-1$ times). The follow-up period was 45 months (median 33 months, 14 days-14 years).

\section{Ventriculoperitoneal shunts}

A total of 31 new VPS were placed. The patients were 3.5 years old on average (median 5 months, 1 day to 16.5 years old). There were 17 girls and 14 boys. The patients who underwent a VPS after a ventriculostomy failure are included, when the first treatment (ETV) was done during the inclusion's period (three patients).

There were ten patients with a posterior fossa lesion (five tumoral lesions, three hemorrhagic lesions, two cysts), four patients with a tectal or tegmental lesion, eight patients with an aqueductal stenosis, and nine patients with another obstructive etiology (one Chiari I malformation, one with aqueductal membranes after toxoplasmosis, seven myelomeningoceles).

Sixteen patients had a shunt failure (52\%) and 11 underwent a shunt replacement, whereas 5 underwent a ventriculostomy. The mean revision-free time was 24 months (median 7 months, 1 day- 8.8 years). The mean number of revisions was 1.6 times $(0-15$ times). The cause of the first failure was disconnection in two cases, proximal occlusion in five cases, distal occlusion in one case, valve dysfunction in three cases, and infection in two cases $(6 \%$ of the total procedures and $11 \%$ of the patients needing revision). In three cases, we were not able to retrieve the cause of failure from the data. The follow-up period was 57.5 months (median 50 months, 10 days -11.5 years).

\section{Comparison of the two groups}

There were slightly more boys in the ventriculostomy group and more girls in the VPS group. The age was not 
significantly different between the two procedures, but tended to be younger for the shunted patients $(p=0.09)$. The distribution of etiologies is slightly different between the two groups; however, they are all considered as obstructive hydrocephalus (Fig. 1).

The number of revisions per patient was higher for the VPS group $(p=0.06)$. There was a slightly longer follow-up period in the VPS group (mean 57 months vs 45 months, $p=0.31$ ), as this procedure has been performed for a longer time in the two hospitals and only progressively replaced by ETV.

In the ETV group, 8 of 24 patients (33\%) needed a revision, whereas 17 of $33(52 \%)$ of the VPS group had a shunt failure. The revision-free time is not significantly different between the two procedures ( 24 months for VPS and 19 months for ETV, $p=0.75$ ), but tends to be longer in the VPS group.

The majority of patients in the ETV group underwent only one procedure, although some had a second procedure after closure of the first ventriculostomy. In the VPS group, even if a majority underwent only one procedure, some patients had to undergo more than ten operations.

The number of revisions shows a lower number of revisions in the ETV group per patient; however, there might be a bias, as only three children benefited from a reintervention consisting of ETV, and all the other ETV failures underwent VPS placement.

The primary cause of failure in the ETV group was closure of the ventriculostomy, although there might have been a bad appreciation of the underlying physiopathology and an associated mal-resorptive hydrocephalus in a few cases. In VPS patients, shunt failure resulted from proximal or distal occlusion, disconnection, valve dysfunction, or infection.

If the percentage of patients free of revisions is considered over time, with definite follow-up period at 6 months, 1, 2, and 5 years after the initial surgery, the

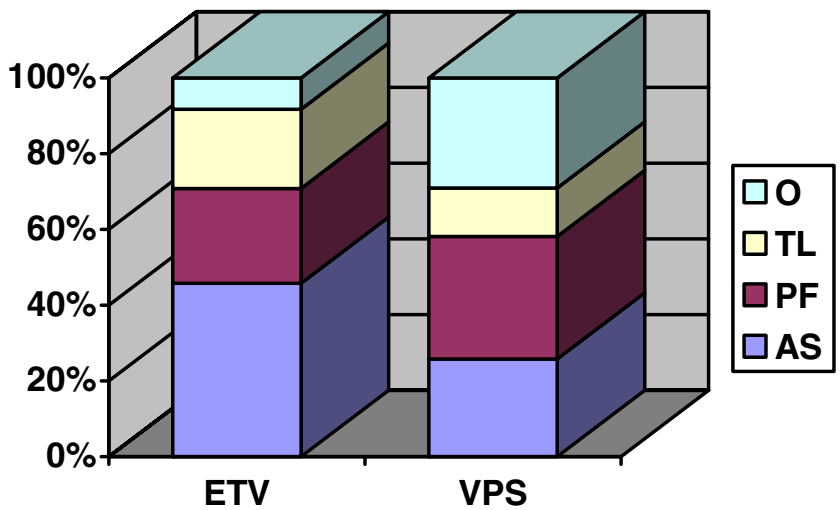

Fig. 1 Etiology of hydrocephalus: There is a majority of cases with aqueductal stenosis in the ETV group, whereas in the VPS group, posterior fossa lesion and other types of lesions are predominant. $P F$ posterior fossa lesion, $A S$ aqueductal stenosis, $T L$ tectal/tegmental lesion, $O$ other dynamic of revisions can be better understood and is shown in Table 1.

There were no statistical differences between the two procedures when analyzing the percentage of patients being revision-free or needing a revision at 6 months, 1, 2, or 5 years (Table 1). The respective failure rates at 2, 5, and 10 years were 26, 26, and $30 \%$ for ETV and 34, 42, and 51\% for VPS, respectively. Although the majority of patients had a follow-up greater than a year (mean follow-up, 52 months; median, 39 months), a number of patients did not reach 2 5 years, and some others were lost to follow up.

There is a constant decrease in the Kaplan-Meier survival curve (Fig. 2) until 1 year for the VPS patients, then a slowing of that curve. For the ETV patients, there is a rapid decrease at the beginning (first 2 months), then a decrease in the slope, and finally, a constant number. The difference between the two curves is not statistically different. The mean time until first revision is 18 months (median 1.1 months) for ETV, whereas it is 24 months (median 8.8 months) for VPS $(p=0.75)$.

There were three unrelated deaths, one in the ETV and two in the VPS group: In all cases, they were at the endpoint of tumor progression

Complications There were no major complications in this series, but three children in the ETV group and one in the VPS group developed sub-dural hematomas. In one case of each group, the sub-dural hematoma had to be drained because it had a significant mass effect and led to clinical symptoms. Some patients underwent over- or underdrainage, sometimes handled with an adjustable valve and sometimes needing a surgical intervention, but those patients, as well as the misplaced shunts, have been analyzed in the failures and not in the complications.

\section{Literature}

A total of 27 studies were found that included 3,768 VPS patients and 1,624 ETV patients in total. Seventeen series analyzed ETV, seven studies examined shunts alone, and three

Table 1 Percentage of patients who were revision-free

\begin{tabular}{lllll}
\hline Pediatric & 6 months & 1 year & 2 years & 5 years \\
\hline ETV & $70 \%$ & $65 \%$ & $52 \%$ & $30 \%$ \\
VPS & $77 \%$ & $66 \%$ & $55 \%$ & $24 \%$ \\
& $p=0.61$ & $p=0.87$ & $p=0.94$ & $p=0.61$ \\
\hline
\end{tabular}

Percentage of patients being revision-free over time for both the ETV and the VPS group. Although there is no significant differences, there is a trend toward less patients needing a revision in the ETV group. At 5 years, there is a sudden drop in both groups due to the fact that some of the patients in the study did not reach this follow-up time (median follow-up time, 39 months). 
Fig. 2 Kaplan-Meier survival curve plotted for VPS and ETV. There is a rapid decrease in the first 3 months for ETV, and then a relative plateau, whereas there is a more constant decrease in the VPS group
ETV vs VPS Kaplan-Meier survival's curve

○ Complete + Censored

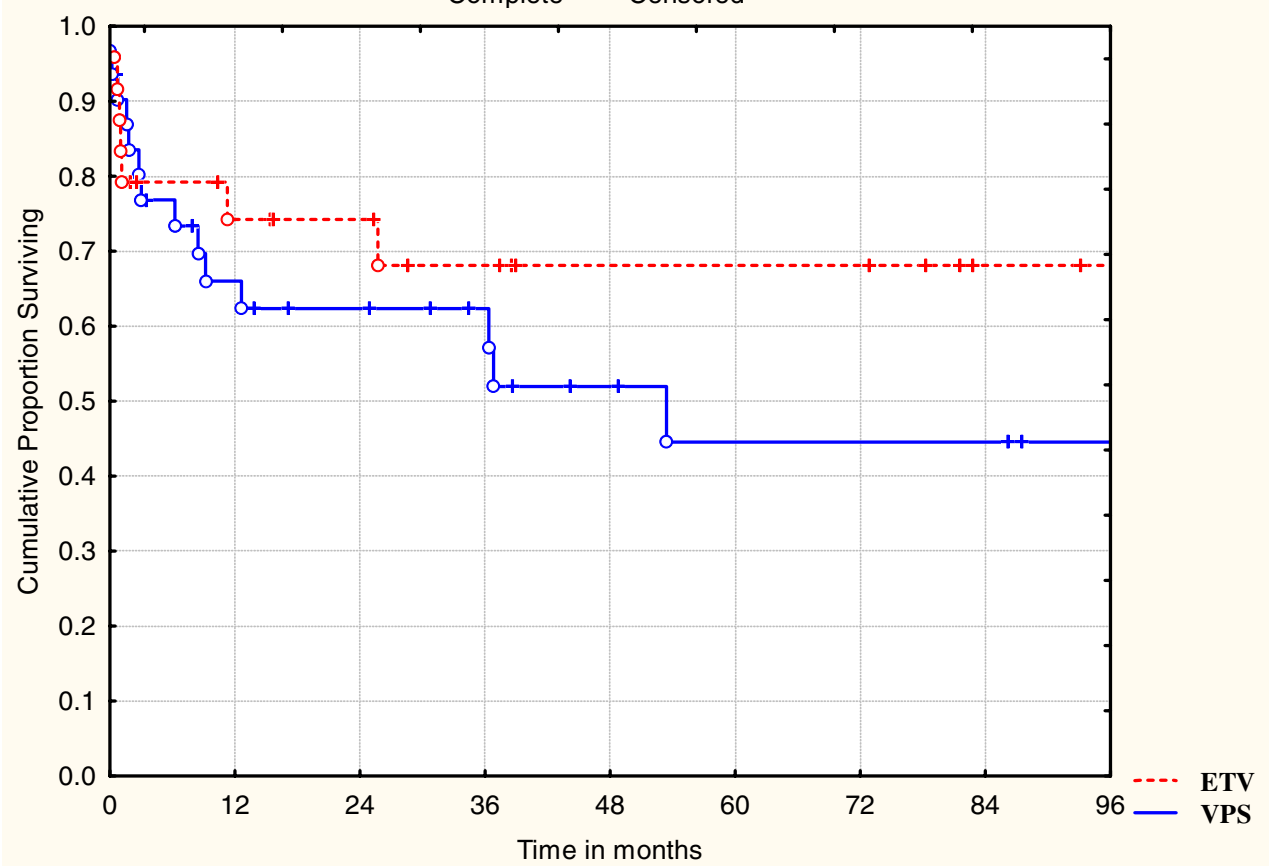

studies compared the two procedures (Table 2) $[2-4,6,10,12$, $14,15,20-22,25-30,32,33,35,36,39-41,43-45]$. As previously stated, meta-analysis could not be performed. However, a mean failure rate can be obtained when adding all the series and weighting them according to their sample size.

A grouping of all patients from the pediatric series published who had benefited from a ventriculostomy revealed a failure rate of $44 \%$. The same analysis with the children who had benefited from a shunt indicated a mean failure rate of $49 \%(p<0.05)$. These numbers are only indications, as there is a large amount of variability in the populations studied in these articles.

In articles reporting ventriculostomies, the failure rate ranges between 8 and $69 \%$, or between 8 and $47 \%$ when the series including infants are excluded. When the followup of the series is greater than 2 years, the lowest failure rate is $15 \%$. In series of VPS, the failure rate range is 27 to $70 \%$, and 56 to $70 \%$ when only analyzing series with a follow-up greater than 2 years. Once again, the failure rate is on the higher side when infants are considered (63\%) [33]. It is important to note that most of the third ventriculostomy series do not consider operations that were planned, but abandoned, during the procedure for technical difficulties or complications, as failures. Only a few series mentioned the number of procedures planned but not achieved, and in those series, the ventriculostomy was not possible in $3.4-7 \%$ of patients. This contrasts the series on VPS, where all patients are accounted for (a drain in a wrong position would be considered as a failure, as there is a need for a second operation).

\section{Discussion}

The management of hydrocephalus is a never-ending problem, and many studies analyzed the treatment options and outcomes [5, 19, 20, 24, 28, 34, 37, 45]. Endoscopic procedures increased in popularity because they provide the opportunity for the patient to be shunt-free. At first, indications for third ventriculostomies were restricted to obstructive hydrocephalus, but some literature suggests that it might also be expanded to some cases of non-obstructive hydrocephalus $[7,16]$. However, the hope of being cured should not be confused with being shunt-free. Hydrocephalus might be treated with an ETV; however, the stomy might fail as would a VPS. Progressively, ETV has been replacing VPS as a treatment for obstructive hydrocephalus, with the belief that no shunt is better than the best shunt. In the series reported herein, all cases had an obstructive hydrocephalus, but sometimes, the pathophysiology behind the hydrocephalus might not be understood, and appreciation of the situation might be difficult (some resorption malfunction might be added to the obstructive etiology).

In our series, at 3 years (median follow-up being 3.25 years), the failure rate of ventriculostomy is $26 \%$, whereas it is $38 \%$ for VPS $(p=0.35)$; although there are statistical differences, there is a trend toward lower failure rate in the ETV group. In literature, the rate of failure of ETV in the literature is highly variable $(8-69 \%)[4-6,18$, 39]. The rate of failure in ventriculoperitoneal patients is highly variable as well $(27-70 \%)[8,9,24,28,37]$. The success of both procedures might vary depending on the 
Table 2 Literature review

\begin{tabular}{|c|c|c|c|c|c|c|c|}
\hline Study & $\begin{array}{l}\mathrm{Nb} \\
\mathrm{ETV}\end{array}$ & $\begin{array}{l}\mathrm{Nb} \\
\mathrm{VPS}\end{array}$ & Mean age ETV & $\begin{array}{l}\text { Mean age } \\
\text { VPS }\end{array}$ & $\begin{array}{l}\text { Failure } \\
\text { rate } \\
\text { ETV (\%) }\end{array}$ & Failure rate VPS & FU \\
\hline Piatt and Carlson [30] & & 727 & & ped & & $\begin{array}{l}73 \text { months } \\
\text { (median survival) }\end{array}$ & \\
\hline Robinson et al. [33] & & 158 & & $<1$ years & & $63 \% 5$ years & 39.8 months \\
\hline Vinchon et al. [41] & & 1564 & & 29.3 months & & $70 \%$ & 10.7 years \\
\hline Tuli et al. [40] & & 717 & & 1.5 years & & $56 \%$ & 11 years \\
\hline Aryan et al. [2] & & 11 & & 4.5 years & & $27 \%$ & 19 months \\
\hline Kestle and Walker [25] & & 201 & & & & $33 \%$ & 1 year \\
\hline Warf [43] & & 152 & & & & $46,00 \%$ & 1 year \\
\hline Jones et al. [21] & 24 & & 8.4 years & & 38 & & \\
\hline Cinalli et al. [6] & 213 & & & & 28 & & 45 months \\
\hline Kim et al. [26] & 32 & & 5.2 years & & 19 & & 19 months \\
\hline $\begin{array}{l}\text { Beems and } \\
\text { Grotenhuis [4] }\end{array}$ & 66 & & 5 months & & 47 & & 4 years \\
\hline Mohanty et al. [28] & 72 & & $?$ (ped) & & 18 & & 15 months \\
\hline Wellons et al. [45] & 13 & & 10 years & & 15 & & 31 months \\
\hline Singh et al. [35] & 29 & & $0-2$ years & & 28 & & $1-18$ months \\
\hline Smyth et al. [36] & 12 & & 9.2 years & & 33 & & 20 months \\
\hline Gorayeb et al. [15] & 36 & & 4.7 months & & 36 & & 47 months \\
\hline Koch and Wagner [27] & 16 & & 3 months & & 69 & & 29 months, median 25 \\
\hline Baykan et al. [3] & 210 & & 2 months -10 years & & 8.10 & & 3 months \\
\hline Etus and Ceylan [10] & 25 & & 6 months & & 44 & & 1 year, 8 months \\
\hline Fritsch et al. [12] & 18 & & 4.9 months & & 61 & & 50 months \\
\hline Kadrian et al. [22] & 22 & & $\begin{array}{c}\text { (6-24 months) } \\
0-78 \text { years }\end{array}$ & & 42 & & 5 years \\
\hline Ray et al. [32] & 43 & & & & 30 & & 24 months \\
\hline Warf [44] & 550 & & 14.5 years & & 44 & & 14.3 months \\
\hline Navarro et al. [29] & 136 & & & & 37 & & 3.3 years \\
\hline Tuli et al. [39] & 32 & 210 & 8.1 years & 3.6 years & 44 & $45 \%$ & 1 to 11 years \\
\hline Javadpour et al. [20] & 21 & 26 & 6 weeks (median) & 2 weeks (median) & 67 & na & 18 months \\
\hline Garton et al. [14] & 28 & 28 & & & 46 & $60 \%$ & 34.7 months \\
\hline
\end{tabular}

Twenty-seven studies were found in the literature.

$\mathrm{Nb} E T V / V P S$ number of patients included in the study who underwent ETV/VPS. Mean age ETV/VPS mean age at which the procedure was done. Failure rate ETV/VPS the failure rate in percentage. $F U$ the mean follow-up (when not available, the range is given). na not available. ped pediatric series

age of the patient, with a higher failure rate for infants $[4,8$, $15,27,33,42]$.

The difference in failure rate between ETV and VPS in the first 6 months of follow-up might reveal either technical difficulties in the ETV group (small space in front of basilar artery, arachnoid membranes lower down the clivus,...) or a bad appreciation in the selection of the patient for the operation [13]. Unfortunately, late failures do occur in both groups, as evidenced by reports of sudden deaths in the literature $[40,17]$. This implies that long-term follow-up is needed in all patients, and that children who underwent ETV cannot be considered as cured.

Procedure-related complications that are reported in the literature are also different between the two procedures, with more major complications reported with ETV such as basilar artery perforation and diabetes insipidus [1, 3, 17, 29, 34]. On the other hand, some of the complications are the same for both procedures, including infections that sometimes lead to fatal meningitis. The reported complication rate varies from 6 to $11 \%[1,29,34]$. The complications encountered in our series of ventriculostomies are similar to those found in the literature.

It has been questioned whether shunt infections might affect the IQ [23, 31, 38], but to our knowledge, there have been no studies done on cognitive dysfunction after ventriculostomy failure. A rare, but fatal complication in the treatment of hydrocephalus is an acute dysfunction with a rapid increase in intracranial pressure and sudden death, 
which might occur many months or years after the procedure, and seems to happen more frequently in ETV $[17]$ than in shunting procedures $[19,40]$. One hypothesis is that, in shunted patients, there is a progressive dysfunction of the shunt, with either some drainage around the shunt in obstructive failure or within the fibrotic tunnel in disconnection. A second reason might be the patient's and family perception of the disease: Although they are well aware of any symptoms that might be caused by shunt dysfunction, and react promptly by coming to the attention of a medical care giver, there might be a popular and medical belief that third ventriculostomy is a one-time curative procedure, and therefore, the patients or their families might not react to the first signs of re-obstruction. Therefore, follow-up of patients is necessary in all cases, but the management of the patients might not be exactly the same. For example, ETV might not change the size of the ventricles, and the patency of the stomy has to be assessed (with 2-D cine phase contrast or T2-weighted fast spin echo) [11], whereas in the follow-up of shunts, ventricular size might be assessed, as well as continuity of the shunt [24].

\section{Conclusion}

Our personal series does not enable us to state that third ventriculostomy is a better treatment for obstructive hydrocephalus than shunt. However, there is a tendency in longterm follow-up for ventriculostomy to be associated with less revisions and a larger revision-free time. The same trend, with a lower failure rate, is seen in the literature. However, the morbidity associates to the procedure, according to literature, might be higher in ventriculostomies than in VPS. We would, therefore, advise to carefully select the patients in which ETV might be of benefit and to keep it as the treatment of choice in obstructive hydrocephalus of those patients.

Patient awareness is extremely important, as late obstruction might occur with both procedures. The patients and their families should be followed on long-term basis and informed on signs and symptoms that might occur in recurring hydrocephalus.

\section{References}

1. Abtin K, Thompson BG, Walker ML (1998) Basilar artery perforation as a complication of endoscopic third ventriculostomy. Pediatr Neurosurg 28(1):35-41

2. Aryan HE, Meltzer HS, Park MS, Bennett RL, Jandial R, Levy ML (2005) Initial experience with antibiotic-impregnated silicone catheters for shunting of cerebrospinal fluid in children. Childs Nerv Syst 21(1):56-61

3. Baykan N, Isbir O, Gercek A, Dagcnar A, Ozek MM (2005) Ten years of experience with pediatric neuroendoscopic third ventri- culostomy: features and perioperative complications of 210 cases. J Neurosurg Anesthesiol 17(1):33-37

4. Beems T, Grotenhuis JA (2002) Is the success rate of endoscopic third ventriculostomy age-dependent? An analysis of the results of endoscopic third ventriculostomy in young children. Childs Nerv Syst 18(11):605-608

5. Brockmeyer D, Abtin K, Carey L, Walker ML (1998) Endoscopic third ventriculostomy: an outcome analysis. Pediatr Neurosurg 28 (5):236-240

6. Cinalli G, Sainte-Rose C, Chumas P, Zerah M, Brunelle F, Lot G et al (1999) Failure of third ventriculostomy in the treatment of aqueductal stenosis in children. J Neurosurg 90(3):448-454

7. Cinalli G, Salazar C, Mallucci C, Yada JZ, Zerah M, Sainte-Rose C (1998) The role of endoscopic third ventriculostomy in the management of shunt malfunction. Neurosurgery 43(6):13231327 (discussion 1327-1329)

8. Davis SE, Levy ML, McComb JG, Masri-Lavine L (1999) Does age or other factors influence the incidence of ventriculoperitoneal shunt infections? Pediatr Neurosurg 30(5): 253-257

9. Enger PO, Svendsen F, Wester K (2003) CSF shunt infections in children: experiences from a population-based study. Acta Neurochir (Wien) 145(4):243-248 (discussion 248)

10. Etus V, Ceylan S (2005) Success of endoscopic third ventriculostomy in children less than 2 years of age. Neurosurg Rev 28 (4):284-288

11. Fischbein NJ, Ciricillo SF, Barr RM, McDermott M, Edwards MS, Geary S et al (1998) Endoscopic third ventriculocisternostomy: MR assessment of patency with 2-D cine phase-contrast versus T2-weighted fast spin echo technique. Pediatr Neurosurg 28 (2):70-78

12. Fritsch MJ, Kienke S, Ankermann T, Padoin M, Mehdorn HM (2005) Endoscopic third ventriculostomy in infants. J Neurosurg 103(1 Suppl):50-53

13. Fukuhara T, Vorster SJ, Luciano MG (2000) Risk factors for failure of endoscopic third ventriculostomy for obstructive hydrocephalus. Neurosurgery 46(5):1100-1109 (discussion 1109-1111)

14. Garton HJ, Kestle JR, Cochrane DD, Steinbok P (2002) A costeffectiveness analysis of endoscopic third ventriculostomy. Neurosurgery 51(1):69-77 (discussion 77-78)

15. Gorayeb RP, Cavalheiro S, Zymberg ST (2004) Endoscopic third ventriculostomy in children younger than 1 year of age. J Neurosurg 100(5 Suppl Pediatrics):427-429

16. Grant JA, McLone DG (1997) Third ventriculostomy: a review. Surg Neurol 47(3):210-212

17. Hader WJ, Drake J, Cochrane D, Sparrow O, Johnson ES, Kestle J (2002) Death after late failure of third ventriculostomy in children. Report of three cases. J Neurosurg 97(1):211-215

18. Hopf NJ, Grunert P, Fries G, Resch KD, Perneczky A (1999) Endoscopic third ventriculostomy: outcome analysis of 100 consecutive procedures. Neurosurgery 44(4):795-804 (discussion 804-806)

19. Hoppe-Hirsch E, Laroussinie F, Brunet L, Sainte-Rose C, Renier D, Cinalli G et al (1998) Late outcome of the surgical treatment of hydrocephalus. Childs Nerv Syst 14(3):97-99

20. Javadpour M, Mallucci C, Brodbelt A, Golash A, May P (2001) The impact of endoscopic third ventriculostomy on the management of newly diagnosed hydrocephalus in infants. Pediatr Neurosurg 35(3):131-135

21. Jones RF, Stening WA, Brydon M (1990) Endoscopic third ventriculostomy. Neurosurgery 26(1):86-91 (discussion 91-92)

22. Kadrian D, van Gelder J, Florida D, Jones R, Vonau M, Teo C et al (2005) Long-term reliability of endoscopic third ventriculostomy. Neurosurgery 56(6):1271-1278 (discussion 1278) 
23. Kanev PM, Sheehan JM (2003) Reflections on shunt infection. Pediatr Neurosurg 39(6):285-290

24. Kestle J, Drake J, Milner R, Sainte-Rose C, Cinalli G, Boop F et al (2000) Long-term follow-up data from the shunt design trial. Pediatr Neurosurg 33(5):230-236

25. Kestle JR, Walker ML (2005) A multicenter prospective cohort study of the Strata valve for the management of hydrocephalus in pediatric patients. J Neurosurg 102(2 Suppl):141-145

26. Kim SK, Wang KC, Cho BK (2000) Surgical outcome of pediatric hydrocephalus treated by endoscopic III ventriculostomy: prognostic factors and interpretation of postoperative neuroimaging. Childs Nerv Syst 16(3):161-168 (discussion 169)

27. Koch D, Wagner W (2004) Endoscopic third ventriculostomy in infants of less than 1 year of age: which factors influence the outcome? Childs Nerv Syst 20(6):405-411

28. Mohanty A, Vasudev MK, Sampath S, Radhesh S, Sastry Kolluri VR (2002) Failed endoscopic third ventriculostomy in children: management options. Pediatr Neurosurg 37(6):304-309

29. Navarro R, Gil-Parra R, Reitman AJ, Olavarria G, Grant JA, Tomita T (2006) Endoscopic third ventriculostomy in children: early and late complications and their avoidance. Childs Nerv Syst 22(5):506-513

30. Piatt JH Jr, Carlson CV (1993) A search for determinants of cerebrospinal fluid shunt survival: retrospective analysis of a 14year institutional experience. Pediatr Neurosurg 19(5):233-241 (discussion 242)

31. Ralph K, Moylan P, Canady A, Simmons S (2000) The effects of multiple shunt revisions on neuropsychological functioning and memory. Neurol Res 22(1):131-136

32. Ray P, Jallo GI, Kim RY, Kim BS, Wilson S, Kothbauer K et al (2005) Endoscopic third ventriculostomy for tumor-related hydrocephalus in a pediatric population. Neurosurg Focus 19(6):E8

33. Robinson S, Kaufman BA, Park TS (2002) Outcome analysis of initial neonatal shunts: does the valve make a difference? Pediatr Neurosurg 37(6):287-294

34. Schroeder HW, Niendorf WR, Gaab MR (2002) Complications of endoscopic third ventriculostomy. J Neurosurg 96(6):10321040
35. Singh D, Gupta V, Goyal A, Singh H, Sinha S, Singh AK et al (2003) Endoscopic third ventriculostomy in obstructed hydrocephalus. Neurol India 51(1):39-42

36. Smyth MD, Tubbs RS, Wellons JC III, Oakes WJ, Blount JP, Grabb PA (2003) Endoscopic third ventriculostomy for hydrocephalus secondary to central nervous system infection or intraventricular hemorrhage in children. Pediatr Neurosurg 39 (5):258-263

37. Tamburrini G, Caldarelli M, Di Rocco C (2002) Diagnosis and management of shunt complications in the treatment of childhood hydrocephalus. Rev Neurosurg 1(3)

38. Topczewska-Lach E, Lenkiewicz T, Olanski W, Zaborska A (2005) Quality of life and psychomotor development after surgical treatment of hydrocephalus. Eur J Pediatr Surg 15(1):2-5

39. Tuli S, Alshail E, Drake J (1999) Third ventriculostomy versus cerebrospinal fluid shunt as a first procedure in pediatric hydrocephalus. Pediatr Neurosurg 30(1):11-15

40. Tuli S, Tuli J, Drake J, Spears J (2004) Predictors of death in pediatric patients requiring cerebrospinal fluid shunts. J Neurosurg 100(5 Suppl Pediatrics):442-446

41. Vinchon M, Fichten A, Delestret I, Dhellemmes P (2003) Shunt revision for asymptomatic failure: surgical and clinical results. Neurosurgery 52(2):347-353 (discussion 353-356)

42. Wagner W, Koch D (2005) Mechanisms of failure after endoscopic third ventriculostomy in young infants. J Neurosurg 103(1 Suppl):43-49

43. Warf BC (2005) Comparison of 1-year outcomes for the Chhabra and Codman-Hakim micro precision shunt systems in Uganda: a prospective study in 195 children. J Neurosurg 102(4 Suppl):358362

44. Warf BC (2005) Comparison of endoscopic third ventriculostomy alone and combined with choroid plexus cauterization in infants younger than 1 year of age: a prospective study in 550 African children. J Neurosurg 103(6 Suppl):475-481

45. Wellons JC III, Tubbs RS, Banks JT, Grabb B, Blount JP, Oakes WJ et al (2002) Long-term control of hydrocephalus via endoscopic third ventriculostomy in children with tectal plate gliomas. Neurosurgery 51(1):63-67 (discussion 67-68) 